[4] N. K. Bose and Y. Q. Shi, Network realizability theory approach to stability of complex polynomials, IEEE Trans. Circuits and Systems 34(No 2) (1987), 216-218.

[5] N. K. Bose and E. Zeheb, Kharitonov's theorem and stabillity test of multidimensional digital filters, Proc. IEE-G 133 (1986), 187-190.

[6] P. Delsarte, Y. Genin and Y. Kamp, Pseudo-lossless functions with application to the problem of locating the zeros of a polynomial, IEEE Trans. Circuits and Systems 32 (1985), 373-381.

[7] C. V. Hollot and A. C. Bartlet, Some discrete-time counterparts to Kharitonov's stability criterion for uncertain systems, IEEE Trans. Automat. Control 31 (No 4) (1986), 355-356.

[8] E. I. Jury and A. Katbab, A note on Kharitonov-type results in the space of Markov parameters, IEEE Trans. Automat. Control 37(No 1) (1992), 155-158.

[9] A. Katbab, F. Kraus and E. I. Jury, Some Schur-stability criteria for uncertain systems with complex coefficients, IEEE Trans. Circuits and Systems 37 (No 9) (1990), 1171-1176.

[10] W. Krajewski, A. Lepschy, G. A. Mian and U. Viaro, A unifying frame for stability-test algorithms for continuous-time systems, IEEE Trans. Circuits and Systems 37(No 2) (1990), 290-296.

[11] F. Kraus, M. Mansour and E. I. Jury, Robust Schur stability of interval polynomials, IEEE Trans. Automat. Control 37(No 1) (1992), 141143.

[12] I. R. Petersen, A class of stability regions for which a Kharitonovlike theorem holds, IEEE Trans. Automat. Control 34(No 10) (1989), $1111-1115$.

[13] P. P. Vaidyanathan and S. K. Mitra, A unified structural interpretation for some well-known stability-test procedures for linear systems, Proc. IEEE 75 (1987), 478-497.

[14] Z. Zahreddine, An extension of the Routh array for the asymptotic stability of a system of differential equations with complex coefficients, Appl. Anal. (to appear)

Department of Mathematics

Faculty of Sciences

U. A. E. University

Al-Ain

P. O. Box 17551

United Arab Emirates

\title{
UNDERGRADUATE PROJECTS
}

S. K. Houston and N. H. Smith

Abstract: The rationale for, operation of and assessment of undergraduate projects at the University of Ulster are discussed. Specimen project titles are provided.

\section{Introduction}

A debate on undergraduate mathematics teaching in Ireland has recently been started through this Bulletin [1], [2]. It has been continued at a conference organized by the Sub-Commission for Mathematical Instruction of the Royal Irish Academy and held in Dublin in September 1991 (RIA-91), [3].

O'Reilly [1] questioned how we teach mathematics at tertiary level, leaving readers with many "focusing questions" and "questions for exploration". Dickenson et al. [2] described innovative methods of teaching, learning and assessment used at the University of Ulster, and went some way to answering O'Reilly's questions. Ted Hurley (UCG) continued the debate in his plenary lecture "Mathematics at Third Level" at RIA-91. In his lecture he pointed out that

(i) the number of honours graduates in mathematics from Irish Universities per capita is 3.5 times smaller than the number per capita from British Universities;

(ii) $45 \%$ of these Irish graduates entered further study compared to $14.5 \%$ of British graduates.

He concluded that this was an unsatisfactory state of affairs and made some suggestions for remedying the situation such as putting greater emphasis on the links between mathematics and computing. 
The ensuing panel discussion at the Conference [3], on "Developments in Teaching Mathematics" produced other suggestions for making courses more attractive and more relevant to the needs of students seeking employment as mathematicians outside academia. One suggestion from Anthony O'Farrell (Maynooth) was to incorporate a project as part of undergraduate courses.

Project work has been a compulsory part of undergraduate mathematics at the University of Ulster, and before that at the Ulster Polytechnic, since the institution was opened in 1971. At the Ulster Polytechnic, Mathematics was offered as one (or two) subjects within a Combined Sciences degree and a final year project was undertaken in one of the main subjects studied. The University of Ulster has honours and ordinary degrees in Mathematics, Statistics and Computing [2], and includes a final year project. This article is an attempt to share with colleagues our experiences in operating projects and to provide some ideas for use or for further discussion.

\section{Rationale for Project Work}

A project is an extensive piece of work carried out individually by students under supervision. They write and submit a full report on their work and the assessment is based largely on this report. At the University of Ulster, the project comprises one module out of six taken by students in their final year. It contributes equally with other units to the final year assessment and grading of students and they are expected to spend about one-sixth of their time working at it. We have been able to arrange that one day per week is entirely free of lectures and this provides an opportunity for students to work at their project.

The aims of the project module, as specified in the Course Handbook are

(i) to involve the student in a substantial task whose completion within a strictly limited time interval will require inventiveness, knowledge of the subject areas of the course, the ability to exercise critical evaluation and judgements, and the ability to work to tight deadlines and properly to pre-plan schedules of work

(ii) to simulate a situation in professional practice in which the mathematician must be capable of bringing all appropriate resources to bear on the solution of a particular problem,

(iii) to develop the student's ability to think independently, work without tight supervision, and make soundly based decisions,

(iv) to encourage initiative and creativity,

(v) to allow study in depth of a topic which either is not fully treated in the lectures or involves the integration of diverse subject areas,

(vi) to expose the student to a situation in which familiar techniques have to be applied in relatively complex and perhaps unfamiliar settings,

(vii) to stress the importance of a literature search, making use of modern techniques of information retrieval,

(viii) to give further experience in written and oral communication and in the production of a coherent and lucid technical report.

These give an indication of the extent of the project and of the skills which students should develop by undertaking it. In addition, students are expected to make appropriate use of computing hardware and software, and almost all projects require a substantial amount of computing because this is an essential skill for today's mathematicians. The student treats this as a research project and learns many of the basic skills of research work. While it would be useful to give the student an original problem to work on, this is not always possible and indeed not altogether necessary since students will have to make the problem "their own" and contribute their own thinking and doing to various aspects of it. We include lists of all topics we have used later in the article.

\section{Organization}

The process for the organization of final year projects begins in the second term of the penultimate year. Staff in the Mathematics Department are asked to submit titles to the project co-ordinator. It is recommended that each member of staff submit at least two titles and preferably more, with the guarantee that not more than two will be allocated to students. In addition, some colleagues 
from other departments are happy to assist by suggesting a title for projects which they would be prepared to supervise. Where the title is insufficient to make it clear to the project co-ordinator what the project will involve, a short description is requested.

When the complete list of titles has been compiled, it is sent to the students, who are away on placement. They are asked to reply by a fixed date, listing a few project titles in order of preference. It is also suggested that, as an alternative, they provide their own project as a result of their experiences in placement. Such a project must not be duplication of the work done in placement, which is separately assessed anyway, but may be an extension of it.

It is not surprising that some project titles are more popular than others and may be the first choices of several students. However, with 16 staff and about 25 students, it has been found possible to allocate projects without having to go below the third preference, and even then it has been necessary to go as far down as the third usually only when a student has replied after the specified date and other allocations have been made.

It is considered to be essential that each student should have a supervisor who is a member of the Mathematics Department so that there is someone who is ultimately responsible for ensuring that the project proceeds satisfactorily. Thus, if the project chosen is not one of those offered by a member of the Department, someone within it is asked to act as joint supervisor. In asking colleagues to act in that capacity consideration is given by the project co-ordinator as to whether a particular mathematical skill is required as well as to the overall supervisory responsibilities of colleagues in an attempt to share the duties fairly evenly. Once student and supervisor(s) have been matched up, it is left to both parties to make contact.

It was recommended that work should start a few weeks before the beginning of the academic year. To a considerable extent the arrangements for students meeting supervisors during the lifetime of the project is left to those concerned. While it is important that regular meetings are held so that the momentum of the work is sustained, their frequency and duration depend on factors such as the amount of assistance required and the supervisor's personal methods of carrying out their duties. A short interim report was requested from the students by the end of January. That gave all parties some idea of what had been done, what remained to be done and whether any remedial action needed to be taken. The report does not influence the final assessment. The main report had to be submitted by the end of the first week of the Easter vacation. However, students were strongly recommended to have their reports ready by the end of the second term; the extra week was available only to take care of last minute hitches in printing and binding. In the future, University regulations will require that the time-scale be changed. Instead of there being six modules each lasting for a year, there will be three modules in each of two semesters. Thus the project will have to be completed in about half the number of weeks formerly available, although the total number of hours should remain about the same. The effects of this change on the nature and management of projects will be of interest.

\section{Assessment}

The importance placed on the project has been mentioned above. In the case of the first cohort of the degree in Mathematics, Statistics and Computing each project report was read by two assessors and marks were awarded on the basis of the report and on the work done during the year. Where a project was supervised jointly the assessors were the two supervisors; in the case of single supervision another member of the Department is the second assessor. Such a person need not have any particular expertise in the subject area of the project, since students are required to present their reports in such a way that they can be readily understood by anyone who has reached the same general level as themselves in the taught units of the course. Initially the assessors mark the projects independently and justify their conclusions in written reports. They then discuss their findings and agree a common mark. 
Marks are awarded according to the following scheme.

Cresentation, organization and Clarit

$35 \%$

Content and Results

$30 \%$

Student Understanding

$20 \%$

Student Effort and Initiative

$15 \%$

It can be seen from the first heading that much emphasis is placed on the student's ability to communicate through the written word; this is one of the main ways in which the project is different from the taught units. Clearly, it is not the case that both assessors are able to award marks under the fourth heading. If an assessor were involved only slightly or not at all in the supervision, he or she must rely on the other's judgement in awarding a mark under that heading. As with the taught units the assessment of the project is subject to the review of the external examiner, and the award of marks is subject to their approval.

The procedure for the assessment of the first cohort of the degree in Mathematics, Statistics and Computing was much the same as it was in the degree in Combined Sciences in which the Department participated. In the latter, only a small number of students did projects in Mathematics each year and the Department was not involved in the assessment of projects in other areas. As a result it was impossible to determine whether the projects were being assessed according to a uniform standard. However, there were 22 projects in the first cohort of the degree in Mathematics, Statistics and Computing and all members of the Department were assessors. It was then possible to look more carefully at the problem of uniformity. It has been suggested that, after the assessors have reported, two people should take an overview of all the projects, and, in consultation with the assessors, modify the marks so that they reflect the rank order. Clearly, such a scheme would create extra work but would lead to greater confidence in the uniformity of assessment

\section{Specimen Titles}

1. Computer-aided analysis and design of circular waveguides.

2. Planetary rings.
3. Student selection and predicting student success: a Bayesian analysis.

4. Topographic mapping - a study of algorithms.

5. The application of sensitivity analysis in linear regression to detect potential carriers of Duchenne muscular dystrophy.

6. The development of a computer graphics package for portfolio diversification of securities using quadratic programming.

7. Attitudes to mathematics.

8. The problem of multiple visits in clinical trials.

9. A statistical measurement of plagiocephaly in babies.

10. A generalized printer.

11. War games and arms races.

12. A numerical study of diffusion-reaction equations.

13. PERT network CAD package.

14. Investigation of hidden line removal within drawing programs.

15. A computer-based octree modelling system.

16. To ascertain the economic advantage of notifying the retrospective testing procedure for defective output.

17. Development of a software package for the administration of placement.

18. A study of population models using differential equations.

19. The complex eigensolution of symmetric and unsymmetric matrices.

20. Development of a rule-based expert system giving guidance to architects and builders on the housing needs of disabled people.

21. Examination of relationship between meteorological and environmental factors and the growth of fungi in an area of mixed forest.

22. Conway's theory of games.

23. Structure of $A A^{\prime}$ for design matrices.

24. Modelling the duration of spells in a geriatric hospital.

25. Mathematica: a system for doing mathematics.

26. The simulation of a CNC routing cell using Witness.

27. Identifying the mathematics potential of students entering access courses. 
28. Trajectories of supersonic projectiles subject to realistic air-resistance.

29. An LL(1)-grammar conformance checker.

30. Testing for quantitative and qualitative interactions in clinical trials.

31. Preparation of open learning material via Symbolator and Latex.

32. An introduction to the analytic hierarchy process.

33. Design of a computer package for a central heating system.

34. Optimum coupling distribution in waveguide design.

35. The prisoner's dilemma and similar games.

36. Design of a computer package for assisting in the drawing up of class and staff timetables.

37. The modelling and analysis of cranial evoked potentials.

38. Computerization of a credit union.

39. Numerical approximation of zeros of polynomials using methods of complex analysis.

40. Implementation and investigation of a technique for digital power spectrum estimation: DASE.

41. Stock Controller.

42. Development of an expert system.

43. The use of the median and range of a uniform distribution as indicators of quality characteristics in process analysis.

44. Simulation of a dynamically nested load for a computer numerical control (CNC) routing machine.

45. Analysing clinical trial end-points using pre-treatment information.

46. Generalized procrustes analysis.

47. The effects of an observation on the determination of a regression equation.

48. The effect of temperature on the sales of solid fuel.

Outline of two Project Tasks

1. Numerical Approximation of Zeros of Polynomials using Methods of Complex Analysis.

Results from complex analysis can be used to locate the zeros of polynomials. Numerical Algorithms based on these results have been designed. The project involves (i) understanding the basis of the algorithms, first published in the 1950's;

(ii) writing programs to carry out approximate zero-finding;

(iii) investigating techniques for determining a whole set of zeros of a polynomial.

2. Mathematica: a System for doing Mathematics

This program will perform symbolic manipulation, including differentiation and integration, carry out numerical methods, work with complex functions, evaluate most common special functions and display results on screen or printer. The project explores some aspects of this.

\section{Conclusion}

In this article we have outlined the rationale for project work at undergraduate level and described the operation and assessment of the scheme. We have given examples of project titles recently and currently undertaken by students. We hope colleagues will find this helpful if they introduce project work to their own degree courses.

\section{References}

[1] Maurice O'Reilly, Mathematics at Third Level - Questioning How we Teach, Bulletin Irish Math. Soc. 22 (1989), 50-54.

[2] F. D. T. Dickenson, E. S. Gillespie and S. K. Houston, Mathematics at Third Level - How we Teach, Bulletin Irish Math. Soc. 24 (1990), 48-54.

[3] N. T. Neill and D. Curran, Report on RIA-91 (1991) (private communication).

S. K. Houston and N. H. Smith

Department of Mathematics

University of Ulster

Jordanstown 